\title{
Investigation of the Influence of Charge Derivatization on the Fragmentation of Multiply Protonated Peptides
}

\author{
Guido Sonsmann, Axel Römer, and Dietmar Schomburg \\ Institute of Biochemistry, Köln, Germany
}

\begin{abstract}
The fragmentation of the multiply charged peptides b-chain of bovine insulin and glucagon have been investigated under low energy collision induced dissociation (CID) conditions using an electrospray ion trap mass spectrometer. The influence of charge state, specific amino acids such as aspartate or proline, the location of basic sites, and the derivatization on the fragmentation behavior has been the focus of interest. As a basis for understanding the fragmentation process, the concept of the mobile proton was applied. A set of different derivatives was used to manipulate the sites of protonation of the peptides in order to control and improve the fragmentation behavior. These results can be applied for de novo sequencing, although the sequence-specific fragmentation processes have significant influence on the dissociation behavior of the peptides. (J Am Soc Mass Spectrom 2002, 13, 47-58) (C) 2002 American Society for Mass Spectrometry
\end{abstract}

$\mathrm{T}$ The identification and characterization of proteins by mass spectrometry has been established as a standard operating procedure in the last 20 years $[1,2,3]$. After the human genome was decoded, the exploration of the proteome has become the focus of interest [4]. Electrospray mass spectrometry techniques in particular are suitable for on-line coupling with liquid chromatography systems and therefore allow rapid and direct identification of peptides [5].

Protein characterization is performed after digestion with a specific protease (e.g., trypsin). The masses of the tryptic peptide fragments are then measured to identify the protein (peptide mapping). The use of trypsin has been favored because a basic amino acid is placed at the C-terminus of the peptide products with the exception of the original C-terminus of the protein [6]. Under ESI-MS conditions these peptides are usually doubly protonated. They tend to undergo charge separation reactions giving intensive fragmentation series (usually singly charged $y$ - and b-ions [7]) revealing sequence information. Not all cleavage sites are cut by the enzyme. This is either caused by inaccessibility for the digestive peptidase or by sequence specific hindrance (proline at the C-terminal side of Lys or Arg prevents cleavage by trypsin). These peptides, known as partials, contain more than one basic amino acid. The charge state of these peptides easily reaches four or five protons and is related to the number of basic amino acids

Published online November 20, 2001

Address reprint requests to Dr. G. Sonsmann, Institute of Biochemistry, Zuelpicher Str. 47, 50674 Köln, Germany. E-mail: g.sonsmann@uni.koeln.de
[8]. More fragmentation reactions are observed because of the increased protonation state. Fragment ions of different charge states occur, complicating the straightforward interpretation of the spectrum. Especially the correlation between the signals and the different fragment ion series is ambiguous. Chemical modification reactions (also known as derivatizations) at the basic sites of peptides have been used to improve the fragmentation process [9]. The preformed charge of the derivative seems to count for an important role in the dissociation behavior of peptides [10]. The aim of many derivatization attempts was to place additional charges on the peptide $[11,12,13]$. In combination with fast atom bombardment measurements the ionization efficiency has been increased as well and the attachment of an additional charge to the N-terminus improved the fragmentation along the peptide backbone [27]. These fixed charges allow only charge-remote fragmentation of the peptide backbone to produce ions with charge retention at the N-terminus. Boyd and co-workers [14] proposed two other fragmentation mechanisms (charge site induced and charge site initiated), which lead to intensive fragment ions. Both mechanisms are combined in the theory of a mobile proton that is randomly distributed over the peptide backbone [15, 16, 17]. Although their investigations were limited to singly and doubly protonated peptides, we believe these mechanisms to be applicable to multiply charged peptides as well. The multiple protonation of peptides was investigated previously [18]. In small peptides the number of basic sites determines the maximum charge state [19]. But with the increase of basic sites in peptide the 


\begin{tabular}{|c|c|c|c|}
\hline Chemical modification & Formula & $\begin{array}{l}\Delta \mathbf{m} \\
{[\mathrm{Da}]}\end{array}$ & Charge manipulation effect \\
\hline acetylation & & 42 & decreased basicity \\
\hline $\begin{array}{l}\text { alkylation with } \\
\text { bromoethyltriphenylphosphine }\end{array}$ & & 289 & adding a fixed charge \\
\hline $\begin{array}{l}\text { acylation with chloro- } \\
\text { sulfonylacetyl chloride }\end{array}$ & & 122 & $\begin{array}{c}\text { decreased basicity } \\
\text { adding a negative charge }\end{array}$ \\
\hline
\end{tabular}

Figure 1. Derivatization reactions for modification of basic sites in peptides.

Coulombic repulsion seems to restrict the maximum number of charges.

However, with consideration of the mobile-proton concept increased protonation of the basic side chains might restrain the mobility of the mobile proton. Because of Coulombic repulsion the mobile proton is inhibited to move randomly across the whole peptide backbone. It might be fixed to a certain protonation site as well. Therefore, the fragmentation and the sequence information is expected to be limited to certain regions of the peptide with higher charge states. The C-terminus carrying a carboxylic group is preferred to sustain a negative charge. The mobile proton is probably attracted from this negative charge leading to intensive fragmentation at the C-terminus.

First observations of the influence of negative charges on the dissociation behavior of peptides were reported by Burlet et al. [20] and Cox et al. [21]. Oxidation of free cysteine to cysteic acid introduced a negative charge on the peptide and changed the dissociation behavior dramatically. As a consequence, a completely different approach has been carried out by Roth et al. who derivatized peptides with a negative charge $[10,22]$ to improve the fragmentation of singly charged peptides in MALDI-PSD spectra. The introduction of a negative charge (e.g., sulfonic acid) is counterbalanced by a second mobile proton. The peptides thus containing two positive charges had an overall singly protonated charge state. The spectrum was dominated by singly charged $\mathrm{y}$-ions clearly identifying the $\mathrm{N}$-terminus. Bauer et al. [23] observed similar dissociation behavior of doubly protonated underivatized peptides and singly charged derivatized peptides as another proof for the existence of a mobile proton.

We were interested in how different derivativization reactions (Figure 1) influence the fragmentation dissociation of multiply charged peptides.

\section{Experimental}

\section{Materials}

Insulin (bovine) and glucagon (human) were purchased from Sigma (Taufkirchen, Germany). Dithiothreitol (DTT), iodacetamide (IAA), chlorosulfonylacetyl chloride (CSAC), ethyl-diisopropylamine, acetic anhydride, triphenylphosphine (TPP), tris-amino methane (TRIS) were obtained from Aldrich (Taufkirchen, Germany). Formic acid and acetic acid were obtained from Merck. Acetonitrile was of analytical grade and obtained from Merck (Darmstadt, Germany). Tetrahydrofuran and bromoethane were freshly destilled.

\section{Cleavage of Disulfide Bonds and Carbamidation of Free Cysteine}

The reaction was carried out as described previously [24]. Insulin was dissolved in $8 \mathrm{M}$ urea in $0.1 \mathrm{M}$ $\mathrm{NH}_{4} \mathrm{HCO}_{3}$ with an approximate protein concentration of $400 \mu \mathrm{M}$. A freshly prepared solution of DTT was added in a 50-fold molar excess with regard to cysteine. After incubation for $30 \mathrm{~min}$ at $57^{\circ} \mathrm{C}$ the reaction mixture was allowed to cool down to room temperature. Iodacetamide at a final concentration of 250 -fold excess with regard to cysteine is added. The solution was kept in the dark at room temperature for $20 \mathrm{~min}$. The reaction was stopped with $1 \mu$ l acetic acid. Salt and buffer were removed with a small reversed phase column (BondElut CS, Langerwehe, Germany).

\section{N-Terminal Derivatization Reactions}

The derivatization of the N-terminus with chlorosulfonylacetyl chloride (CSAC) was performed as described previously [25]. A peptide $(1 \mathrm{nmol})$ was dissolved in 2 $\mu \mathrm{l} 0.02 \mathrm{M}$ sulfonic acid $(2 \mu \mathrm{l} \mathrm{CSAC}$ in $500 \mu \mathrm{l}$ water). 
After evaporation the peptide was dissolved in $20 \mu \mathrm{l}$ THF/ethyl-diisopropylamine (4:1), and $2 \mu \mathrm{l}$ of a $0.1 \mathrm{M}$ solution of CSAC in dry THF was added. The solution was vortexed for $30 \mathrm{~s}$ and after a total reaction time of 1-2 min, the sample was dried in vacuo and dissolved in $0.1 \% \mathrm{HCOOH} / \mathrm{H}_{2} \mathrm{O} / \mathrm{ACN}$ (1:1) prior to application to the mass spectrometer. The derivatization reaction has been successfully applied in gel digestions [26] with a limit of $300 \mathrm{fmol}$ of protein in the gel.

Acetylation was carried out in a solution containing $10 \%$ acetic anhydride in acetic acid. After $2 \mathrm{~h}$ the solvent was evaporated and the sample was redissolved for 20 min in $1 \mathrm{M} \mathrm{NH}_{4} \mathrm{OH}$ to remove O-acetylated side reaction products. After evaporation the samples were stored at $-20^{\circ} \mathrm{C}$. Prior to application to the mass spectrometer the samples were dissolved in $0.1 \%$ $\mathrm{HCOOH} / \mathrm{H}_{2} \mathrm{O} / \mathrm{ACN}(1: 1)$.

The derivatization reagent bromoethyl-triphenylphosphine (Br-TPP) was prepared as described elsewhere [27]. The procedure for derivatization of the $\mathrm{N}$-terminal primary amine with ethyl-triphenylphosphine (TPP) was slightly modified. The reaction was carried out by dissolving a peptide $(0.5-2 \mathrm{nmol})$ in TRIS-buffer solution at $\mathrm{pH}$ 9. A solution of Br-TPP (10 $\mathrm{nmol} / \mu \mathrm{l}$ in $\mathrm{ACN}$ ) was added in a 20-fold molar excess. The sample was vortexed and kept for $3 \mathrm{~h}$ at $37^{\circ} \mathrm{C}$. The peptide derivative was obtained by solid phase extraction $\left(\mathrm{C}_{18}\right.$ reversed phase column, BondElut CS, Langerwehe, Germany) to remove buffer salts. After stepwise elution with $\mathrm{H}_{2} \mathrm{O} / \mathrm{ACN}$ the samples were evaporated. Prior to application to the mass spectrometer the samples were dissolved in $0.1 \% \mathrm{HCOOH} / \mathrm{H}_{2} \mathrm{O} / \mathrm{ACN}(1: 1)$.

\section{Mass Spectrometry}

All data were acquired on an LCQ ion trap instrument (Thermoquest, Bremen, Germany). The samples were injected into the mass spectrometer at a constant flow rate of $1-5 \mu \mathrm{l} / \mathrm{min}$. The experiment conditions were as follows: The spray needle voltage was set to $4.5 \mathrm{kV}$, the heated capillary temperature was $200{ }^{\circ} \mathrm{C}$ and the sheath gas rate was 60 (instrument parameter). Full scan MS spectra were recorded with a mass range from 250-2000 $\mathrm{Da}$. The tandem MS spectra were obtained by setting the isolation width to $3 \mathrm{Da}$. Relative collision energies ranged from 25 to $50 \%$ (internal parameter) decreasing with higher charge states of the precursor ion. The relative collision energy was adjusted to maximum fragmentation efficiency of the parent ions. Single spectra were accumulated for $1 \mathrm{~min}$ (approximately 20-25 spectra). In order to compare the spectra, the relative intensities of the fragmentions (b- and y-ions) were displayed as a bar plot. Therein, light bars represent $y$-ions and black bars b-ions. These bars indicate the positions of fragmentation. From these diagrams changes of dissociation behavior can easily be visualized.

\section{Results and Discussion}

\author{
Native Glucagon
}

Spectra (Figure 2) of native glucagon (HSQGTFTSD ${ }^{10}$ YSKYLDSRRA ${ }^{20}$ QDFVWLMNT) were sequenced by ESI-MS/MS on the LCQ-instrument. MS/MS spectra of each charge state $(+2,+3,+4)$ showed significant changes in their dissociation behavior. Remarkably, a quintuply protonated precursor ion could not be observed, although there are five basic sites in the protein. Note that the b-chain of bovine insulin with five basic sites is quintuply protonated [30]. Presumably the close proximity of the two arginine residues (amino acid 17 and 18) in glucagon prevents the protonation of both of them.

Figure 2a shows that the doubly protonated precursor ion of glucagon undergoes rather poor fragmentation. The ions are mainly fragmentation products from the cleavage at the C-terminal site of aspartate. This rather specific fragmentation has been observed with other proteins and has been investigated elsewhere [28]. The mechanism of this reaction is supposed to be the nucleophilic attack of the deprotonated carboxy group (Figure 3) [29]. Interestingly, no further sequence information of the protein is accessible although there are two charges available for potential fragmentation reactions.

The MS/MS spectrum of the triply charged protein shows additional fragmentation at the $\mathrm{N}$ - and C-termini. Note that there are doubly charged $b$ - and y-ions. This result suggests that a mobile proton on both ends of the protein is responsible for the fragmentation. The fragmentation process can be characterized as a charge separation mechanism, although the smaller singly charged peptides cannot be detected because of the detection limitation for low mass peptides of the ion trap. Therefore, the doubly charged fragments are of reasonable intensity.

The quadruply charged precursor ion shows only intense fragmentation at the C-terminus (Figure 2c). The occurrence of triply charged b-ions can be explained by the mobile proton located on the $\mathrm{C}$ terminus. The other basic sites (His, Lys, Arg) are protonated by a fixed proton, though not available for intense fragmentation on the peptide backbone. These results also propose a fixed charge on the $\mathrm{N}$-terminal histidine which is withdrawn from the peptide backbone.

\section{Derivatization of Glucagon with Chloro-Sulfonylacetyl-Chloride}

After derivatization of glucagon with sulfonic acid at the N-terminus, spectra of three different charge states $(+2,+3,+4)$ have been analyzed. The spectrum of the doubly charged precursor ion of derivatized glucagon shows an enhanced fragmentation on the $\mathrm{N}$-terminus yielding preferably doubly charged $y$-fragments. The 

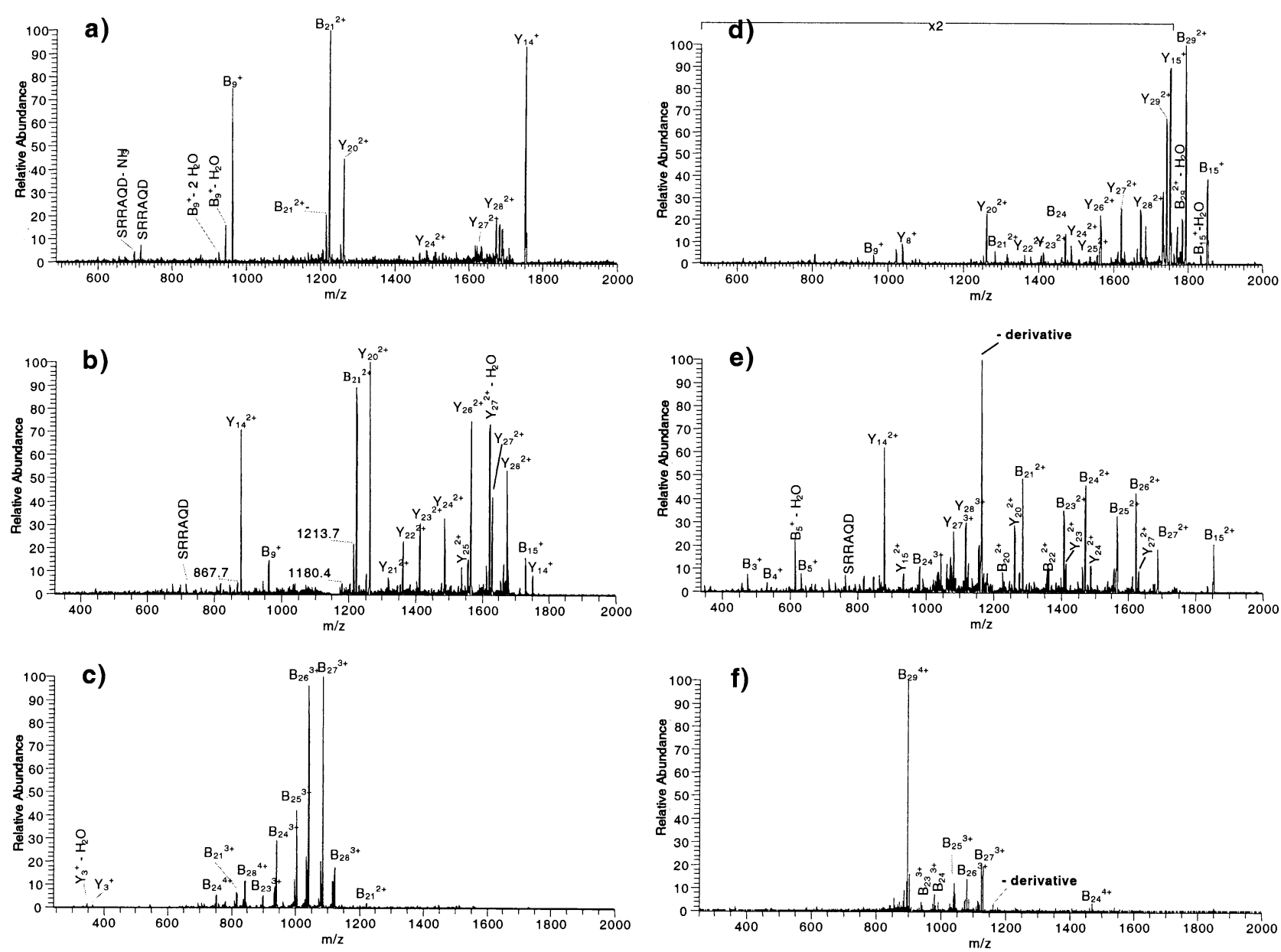

Figure 2. ESI-MS/MS spectra of glucagon (HSQGTFTSD ${ }^{10} Y S K Y L D S R R A^{20}$ QDFVW LMNT) obtained on a LCQ mass spectrometer. (a) doubly protonated, underivatized; (b) triply protonated, underivatized; (c) quadruply protonated, underivatized; (d) doubly protonated, derivatized with CSAC; (e) triply protonated, derivatized with CSAC, and (f) quadruply protonated, derivatized with CSAC.

intensities of the fragments derived from the aspartate induced fragmentation have been decreased (Figure 2d).

The spectrum of the triply charged glucagon (Figure $2 \mathrm{e})$ shows additional $y$-fragment ions and a significant increase of the relative abundance of the b-ions generated by fragmentations at the $\mathrm{C}$-terminus of the protein. The addition of a negative charge at the $\mathrm{N}$-terminus has improved the quality of the y-ions as expected. The fragmentation of the C-terminus cannot be explained that simply. The second proton probably tends to be located preferably at the basic sites in the middle of the protein. Consequently, the third proton has to be distributed along the C-terminus of the protein, which leads to intense fragmentation processes. This assumption is supported by the MS/MS spectrum of the

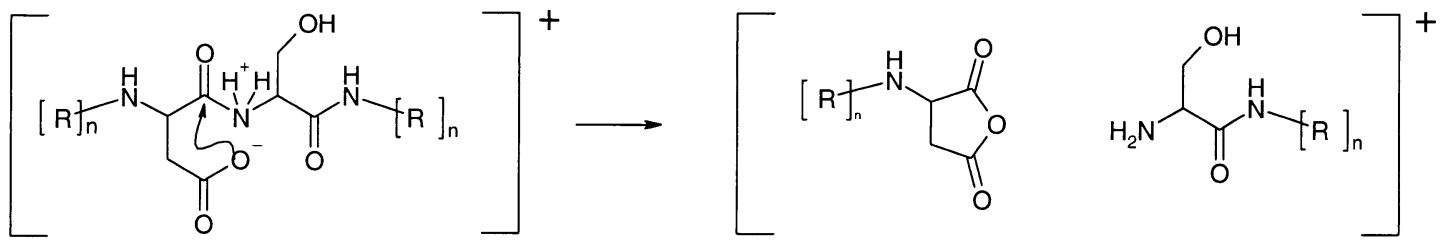

Figure 3. Fragmentation mechanism of the facile bond cleavage at the C-terminal site of aspartate; the acidic proton of the aspartate is transferred on the peptide backbone; the nucleophilic attack leads to cyclic five membered ring (acid anhydride). Note that the mechanism is independent of the overall protonation of the molecule. 

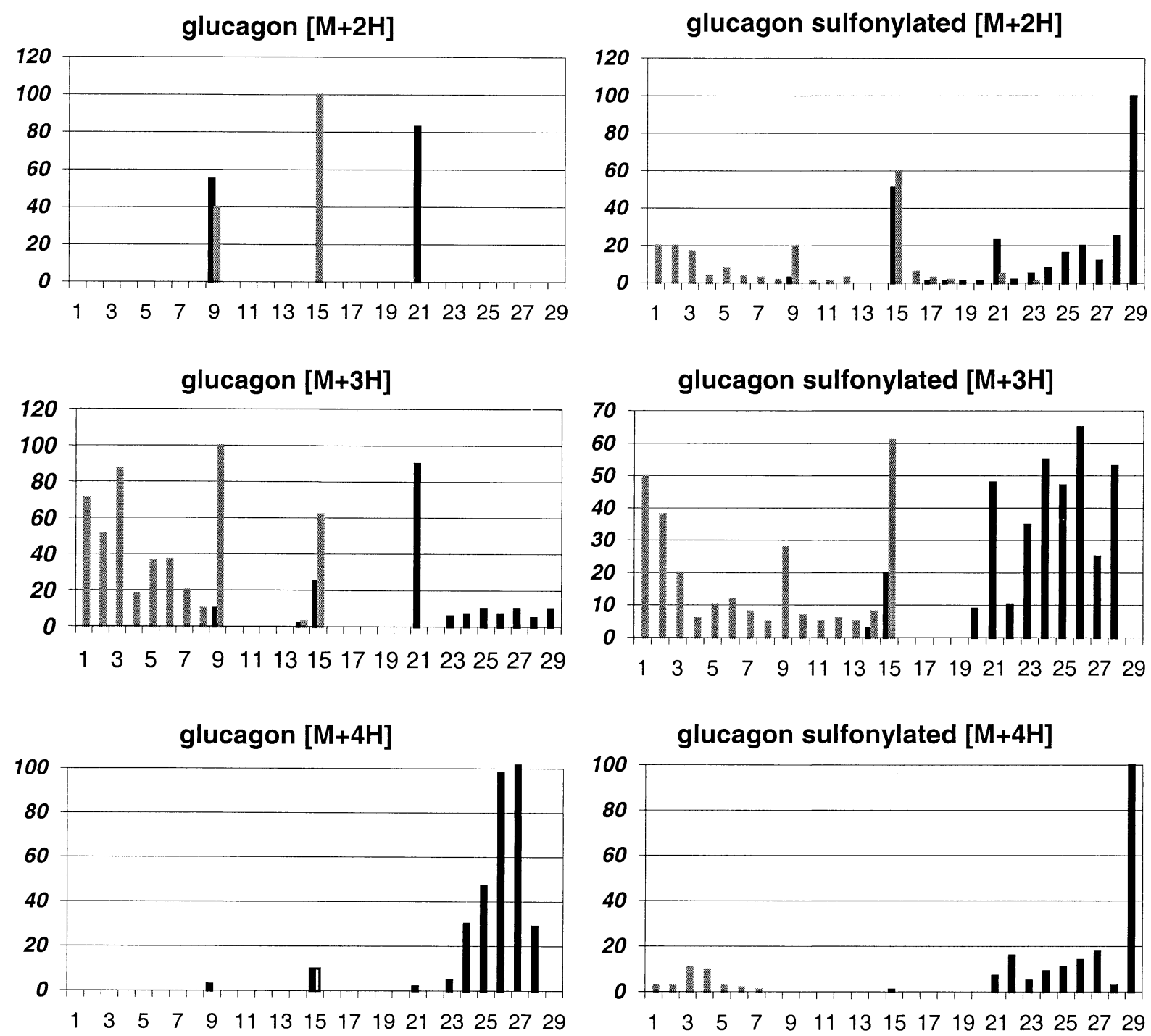

Figure 4. Dissociation behavior of underivatized and sulfonylated glucagon; the number of the amino acid is plotted versus the relative abundance of the fragment ion series; black bars represent b-fragment ions, light bars represent y-fragment ions, respectively; relative intensities $>100 \%$ are caused by the same fragment ions in different charge states; for the triply charged sulfonylated glucagon the ion with $100 \%$ intensity was the neutral loss of water from the precursor ion and therefore of no interest to the sequence information.

quadruply charged glucagon derivative (Figure 2f). Here the spectrum shows several additional $y$-fragments of the N-terminus, although the main fragmention arises from fragmentation caused by the mobile proton at the C-terminus.

All in all, the sequence information obtained from the MS/MS spectra improved dramatically after derivatization (Figure 4). The intensities of the $y$-fragment ions obtained from the triply charged precursor ion have been increased. This fact confirms the role of the sulfonic acid derivative as it attracts the mobile proton. The dissociation close to the N-terminus has been enhanced, although the influence of the charge state prevents the exclusive formation of $y$-fragments as obtained from singly charged peptides [22].

\section{B-Chain of Bovine Insulin}

The b-chain of bovine insulin (FVNQHLC CAM $_{\text {(F) }}$ $\mathrm{GSH}^{10}{ }^{10}$ EALYLVC ${ }_{\text {CAM }}{ }^{20}$ ERGFFYTPKA) resembles a typical tryptic peptide with Lys 28 located near the C-terminus. Arg 22 represents the model for an uncleaved basic site. Additional basic sites (Arg and His) enable the multiple protonation of the peptide. Four different charge states $(+2,+3,+4,+5)$ have been investigated (Figure 6) and compared with the obtained sequence information (Figure 9). Note that Pro 27 is known to have a major influence on the dissociation behavior under ESI-CID conditions [30].

The Cys residues of the b-chain have been alkylated with iodacetamide $\left(\mathrm{C}_{\mathrm{CAM}}\right)$ to prevent side reactions of 

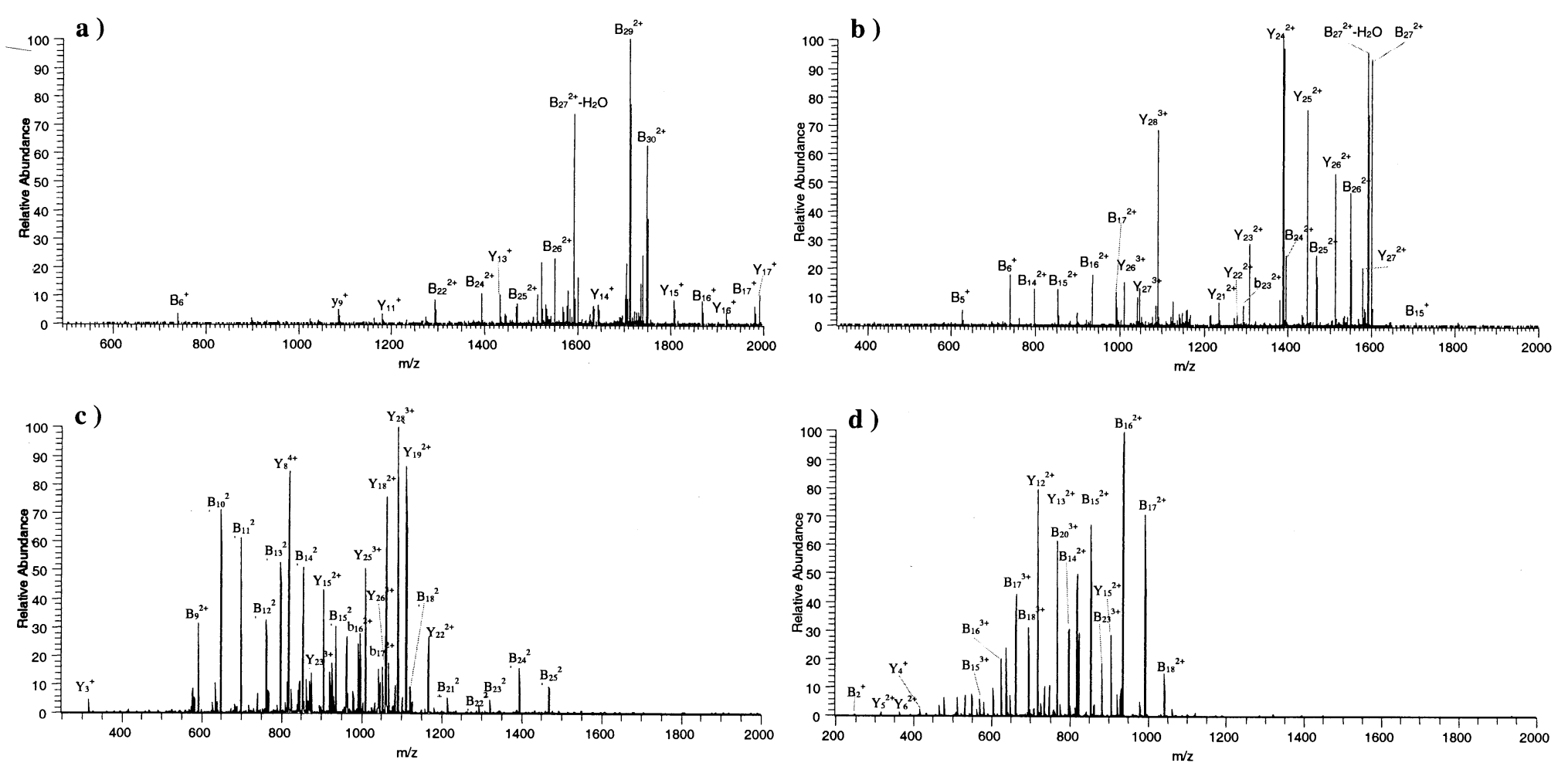

Figure 5. MS/MS spectra of underivatized b-chain of bovine insulin (FVNQHLC ${ }_{\mathrm{CAM}} \mathrm{GSH}^{10} \mathrm{LVEALYLVC}_{\mathrm{CAM}} \mathrm{G}^{20}$ ERGFFYTPKA); (a) doubly charged, (b) triply charged, (c) quadruply charged, and (d) quintuply charged. 

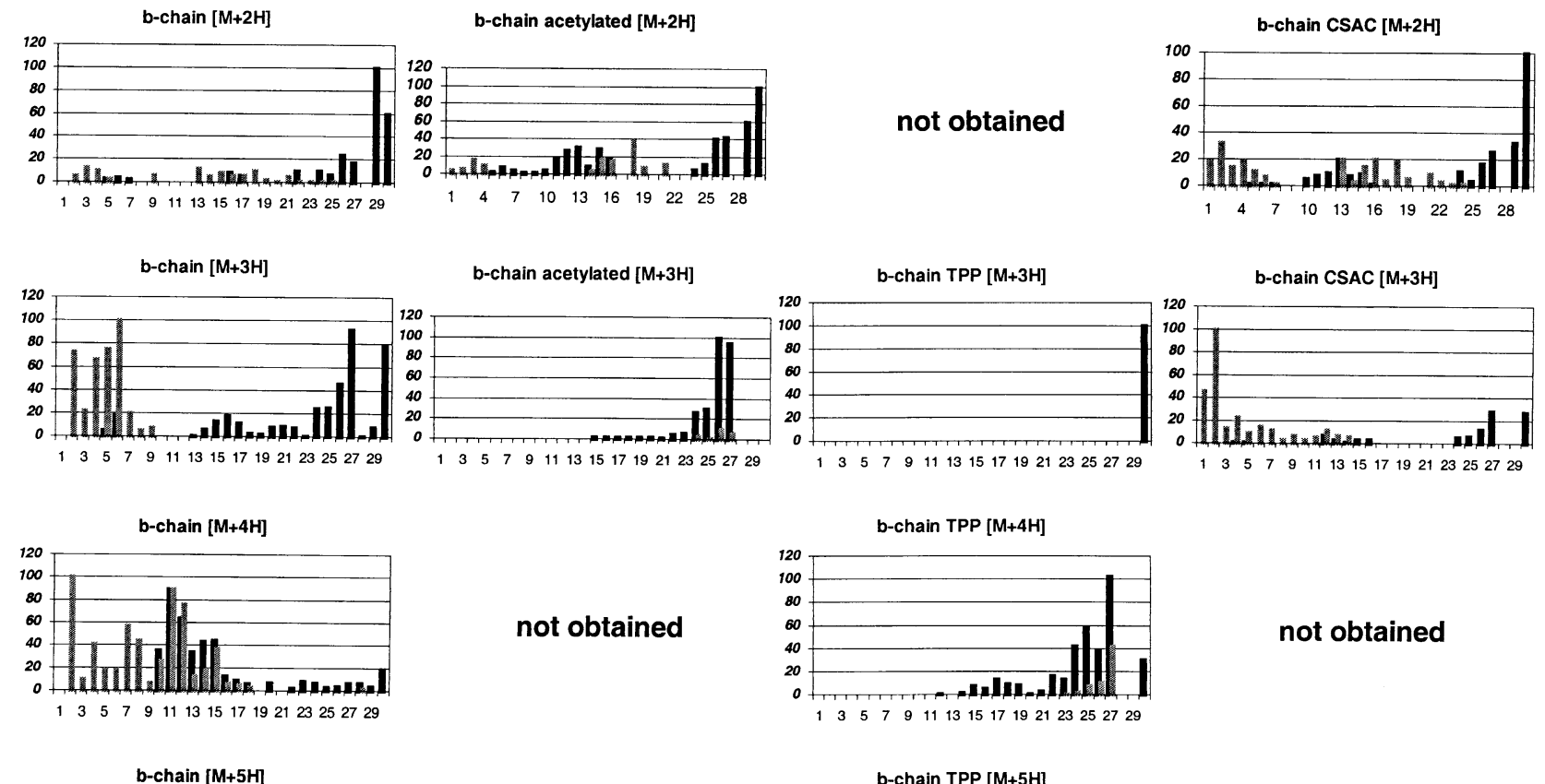

not obtained
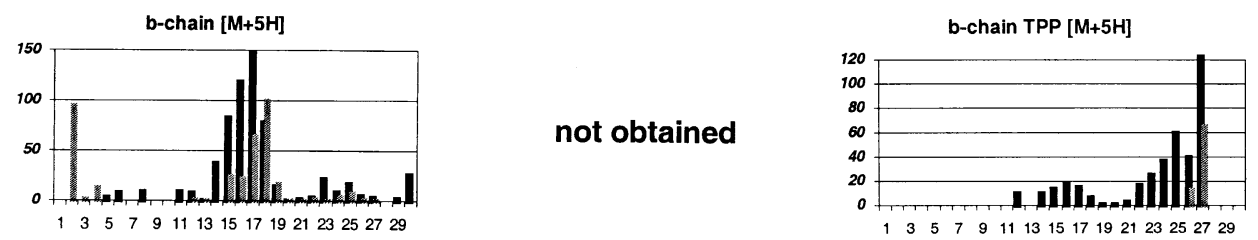

Figure 6. Dissociation behavior of derivatives (acetylated at N-terminus and Lys, TPP at Lys, CSAC at $\mathrm{N}$-terminus) of the $\mathrm{b}$-chain of bovine insulin; the columns contain (from left to right) carbamylated $\mathrm{b}$-chain, acetylated b-chain, TPP derivative of b-chain, and CSAC derivative of the b-chain of bovine insulin. The charge state increases from the top to the bottom row. In each diagram the number of the amino acid is plotted versus the relative abundance of the fragment ions series. (Black bars represent b-fragment ions, light bars represent y-fragments respectively); relative intensities $>100 \%$ are caused by the same fragment ions in different charge states.

the free thiol function. Although the number of possible reactivities in the molecule has been minimized, there is still the amine group of Lys (Pos 29) which undergoes side reactions in derivatizing reactions.

\section{Fragmentation of the Underivatized B-Chain of Bovine Insulin}

The MS/MS spectrum of the doubly charged precursor ion shows rather poor fragmentation (Figure 5a). The main fragment is $b_{29}^{2+}$. The $\mathrm{N}$-terminal side of proline fragmentates easily and undergoes the neutral loss of water $\left(b_{27}^{2+}-\mathrm{H}_{2} \mathrm{O}\right)$. Fragmentation of both the Nterminus and the $\mathrm{C}$-Terminus can be observed with low abundance. The two protons are located at the most basic sites (Arg, Lys) and therefore the fragmentation along the peptide backbone is unfavorable.

Along with the addition of a third charge the number of intensive fragment ions increases (Figure 5b). The series of doubly charged b-fragments can be observed from $b_{14}^{2+}$ to $b_{27}^{2+}$, whereas the $y$-fragment ions yield the series from $y_{28}^{2+}$ down to $y_{17}^{2+}$. From these findings the third proton must be distributed along the peptide backbone inducing fragmentation of the whole se- quence (except the C-terminal proline bond, Pro-Lys). The most intensive fragment ions can be observed at both ends of the peptide (Figure 6).

By adding a fourth proton the spectrum of the quadruply charged precursor ion becomes more difficult to interpret (Figure 5c). The same fragments occur in different charge states, which seems to complicate the spectrum. On the other hand, the uncertainties in the interpretation of single fragment ions can be removed by the same ions appearing in different charge states. The occurence of intensive fragment ions has been shifted towards the middle of the peptide (Figure 6).

From the spectrum of the quintuply charged precursor ion only a few highly charged ions can be observed. Most of the intensive fragment ions are doubly charged fragment ions giving sequence information about the center of the peptide (positions 13 to 19). Assuming that the intensive fragmentation depends on the mobile proton, the change in the dissociation behavior can be explained by a restricted mobility of the mobile proton by the successive protonation of the basic amino acids. The quintuply charged precursor ion is also protonated at the two 


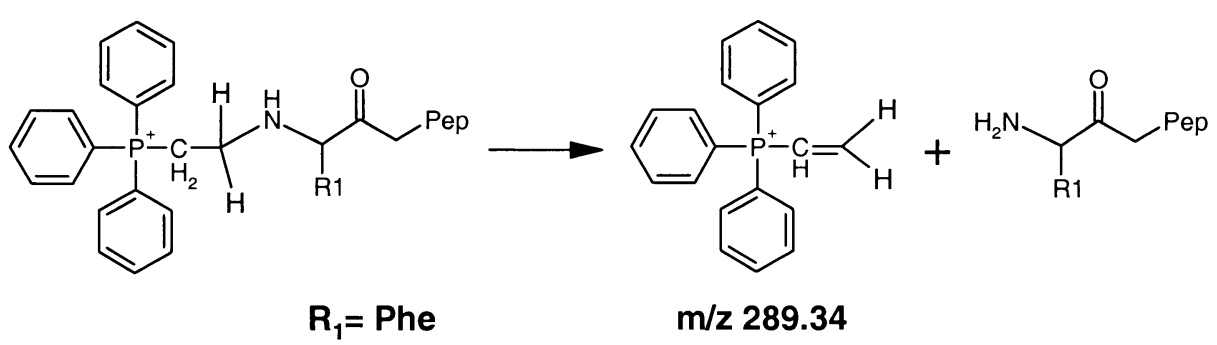

Figure 7. Influence of charge derivatization. Reversed Michael-type reaction; the loss of ethyltriphenyl-phosphine from peptides under ESI-MS/MS conditions can be observed by the detection of the fragment $m / z 289$, if the mass area is not limited by the instrument.

His residues (positions 4 and 9). The mobile proton is somehow trapped between His 9 and Arg 22. It has been observed that with increasing charge the probability of the location of the mobile proton can be restricted to a limited area of the peptide backbone [14].

The influence of His on the dissociation behavior has been investigated elsewhere [31]. Synthetic peptides with different positions of His were found to prevent fragmentation in close proximity to the protonated His residue. The poor fragmentation close to basic amino acids can also be observed with the b-chain of bovine insulin (Figure 6).

As a result, the investigation of different charge states is useful to gain sequence information of the whole peptide. For future analysis, e.g., with a Fourier transform-ion cyclotron resonance (FT-ICR) mass spectrometer, the charge state of the fragment can be determined. If the charge state of the fragment ion is known, the combination of the spectra from different charge states can be used to obtain a complete deconvoluted spectrum, which will reveal the complete sequence information of the peptide.

\section{Derivatization of the B-Chain of Bovine Insulin with TPP}

The addition of a fixed positive charge on the $\mathrm{N}$-terminus increases the number of charge stages $(+2,+3,+4,+5$, $+6)$. Surprisingly the derivative is unstable under ESIMS/MS conditions. The only fragment ion of the triply charged precursor ion corresponded to the loss of the TPP (loss of $289 \mathrm{Da}$ ). The same phenomenon was observed for the triply and quadruply charged precursor ions of the bis derivative from the b-chain of insulin (data not shown). The proposed mechanism for the elimination of the derivative (Figure 7) has been described before with plasma desorption mass spectrometry as a reversed Michael-type reaction [33].

The MS/MS spectrum of the quadruply charged precursor ion (Figure 8a) shows a completely different dissociation behavior compared to the underivatized bchain (Figure 9). With the fixed charge at Lys dissociation is no longer observed near the N-terminus. The formation of $y$-fragment ions characterizing the N-terminal sequence has been completely suppressed. Instead the formation of b-fragment ions at the C-terminus is favored. The same fragmentation scheme can be observed with higher charge states. Even doubly charged $\mathrm{y}$-fragments of the C-terminus can be observed (Figure 8b).

The additional fixed charge at the lysine prevents the mobile proton from inducing fragmentation along the peptide backbone close to the N-terminus. This can be explained with a fixed charged at the N-terminus, because the MS/MS spectra of the bis derivative (TPP derivatization at Lys and the $\mathrm{N}$-terminus) resemble those of the mono derivative. With the second TPP moiety placed on the $\mathrm{N}$-terminus there is certainly a fixed charge. If both derivatives have the same fragmentation behavior, they probably have the same initial protonation. From those spectra it is difficult to decide whether or not the enhanced fragmentation of the C-terminus is a charge-remote mechanism which is suggested by the intensive fragmentation at the C-terminus combined with a fixed charge at the lysine. With the lower charged precursor ions exclusively undergoing elimination of the TPP it seems to be necessary to have additional protons on the peptide to get fragment ions. For this reason the contribution of the mobile proton to the fragmentation process seems to be essential.

In this case, the fragmentation process has been influenced to produce only sequence information of the C-terminus, which is in agreement with other observations [34] detecting improved fragmentation efficiency close to the TPP moiety at the N-terminus. The instability of the derivative is a disadvantage for the interpretability of the spectra because of the appearance of fragment ions, which have lost the reactant. These additional signals may lead to misinterpretation of the spectrum.

\section{Acetylation of the B-Chain of Bovine Insulin}

Acetylation of the primary amines (N-terminus, Lys) lowers the basicity of the peptide [14, 19]. Only two different charge states $(+2,+3)$ of the acetylated peptide are observed (Figure 9). The spectrum of the doubly protonated precursor ion has been improved with respect to the fragmentation in the center of the peptide (Figure 9a). From the spectrum of the triply 


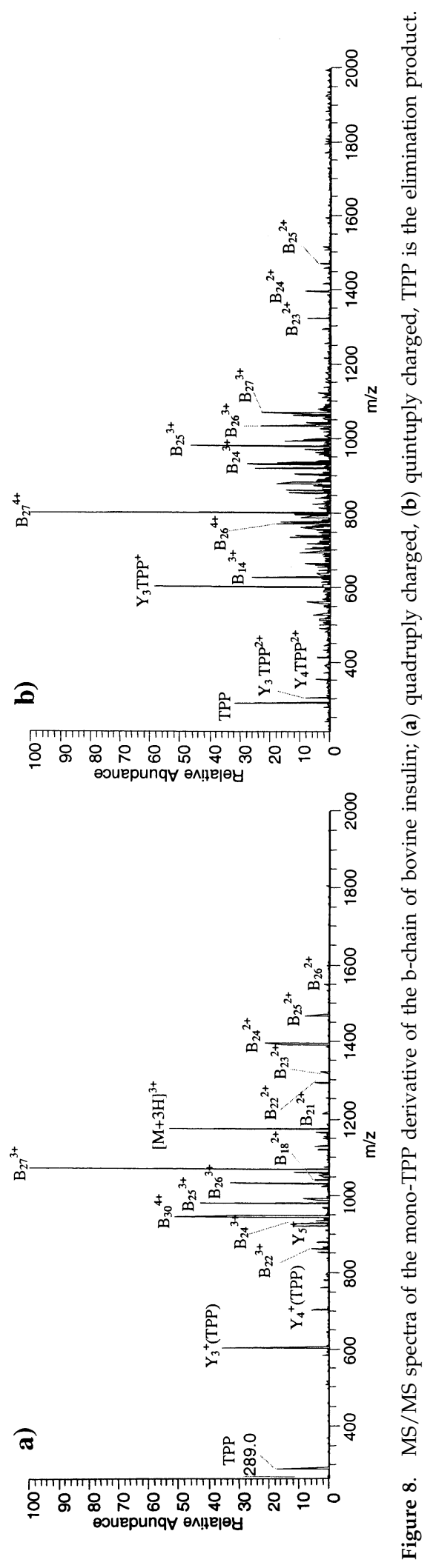

charged precursor ion (Figure $9 b$ ) only b-fragment ions $\left(b_{12}^{2+}\right.$ to $\left.b_{27}^{2+}\right)$ have been observed. A few $y$-fragment ions $\left(\mathrm{y}_{3}^{+}\right.$to $\left.\mathrm{y}_{6}^{+}\right)$derived from charge separation reactions clearly confirm the sequence of the C-terminus. Obviously, the peptide sequence can easily be determined because the formation of $y$-fragment ions has been suppressed. The same dissociation behavior has been observed with the acylation of the b-chain of bovine insulin with bromo-nicotinic acid (data not shown). Originally, the derivatization with bromo-nicotinic acid N-hydroxy succinimid was utilized for selective modification of the N-terminus [32]. The isotope distribution of bromine was applied to differentiate between $b$ - and $y$-ions. However, the decrease in basicity of the acylated (acetylation and acylation with bromo-nicotinic acid) peptide is the reason for a different dissociation behavior compared to the underivatized peptide.

\section{Derivatization of the B-Chain of Bovine Insulin with Chloro-Sulfonylacetyl-Chloride}

After derivatization with chloro-sulfonylacetyl-chloride a mixture of mono and bis derivatives has been detected. MS/MS spectra have been observed only for two charge states $(+2,+3)$ (Figure 9). Obviously, the negative charge decreases the overall charge state of the precursor ions. The mono adduct was confirmed from the MS/MS spectra to be modified merely at the N-terminus.

The MS/MS spectrum of the doubly charged precursor ion shows an intensive ion from the loss of the reagent (Figure 9c). This fragment ion can be used for the unambiguous identification of the N-terminal amino acid by stepwise searching of a reasonable mass difference. In this case the fragment ion $\mathrm{y}_{29}^{2+}$ can be identified by the correct mass differences $(78.5 \mathrm{~m} / \mathrm{z}$ for Phe, doubly charged) and the correct charge state (doubly charged fragment ion). At least the doubly charged $\mathrm{y}$-fragment ions for seven $\mathrm{N}$-terminal amino acids can be determined $\left(\mathrm{y}_{29}^{2+}-\mathrm{y}_{22}^{2+}\right)$. Remarkably, several other $\mathrm{y}$-fragment ions $\left(\mathrm{y}_{17}^{+}-\mathrm{y}_{7}^{+}\right)$with a charge localization at the C-terminus can be detected. In comparison to the spectrum of the underivatized b-chain, the fragmentation at the $\mathrm{N}$-terminus and the abundance of $y$-fragment ions have been improved. The second proton has been abstracted from the Arg (position 22) towards the $\mathrm{N}$-terminus and functions now as a mobile proton inducing intensive fragmentation on the $\mathrm{N}$ terminus.

The fragmentation of the triply charged precursor ion shows the same tendency in its dissociation behavior. Mostly $y$-fragment ions revealing the sequence at the N-terminus are detected, whereas the intensities of the b-fragment ions have diminished (Figure 6).

By placing a negative charge on the N-terminus the fragmentation behavior has been directed towards the $\mathrm{N}$-terminus. This process seems to be independent from the charge state of the precursor ion. Additionally, the 

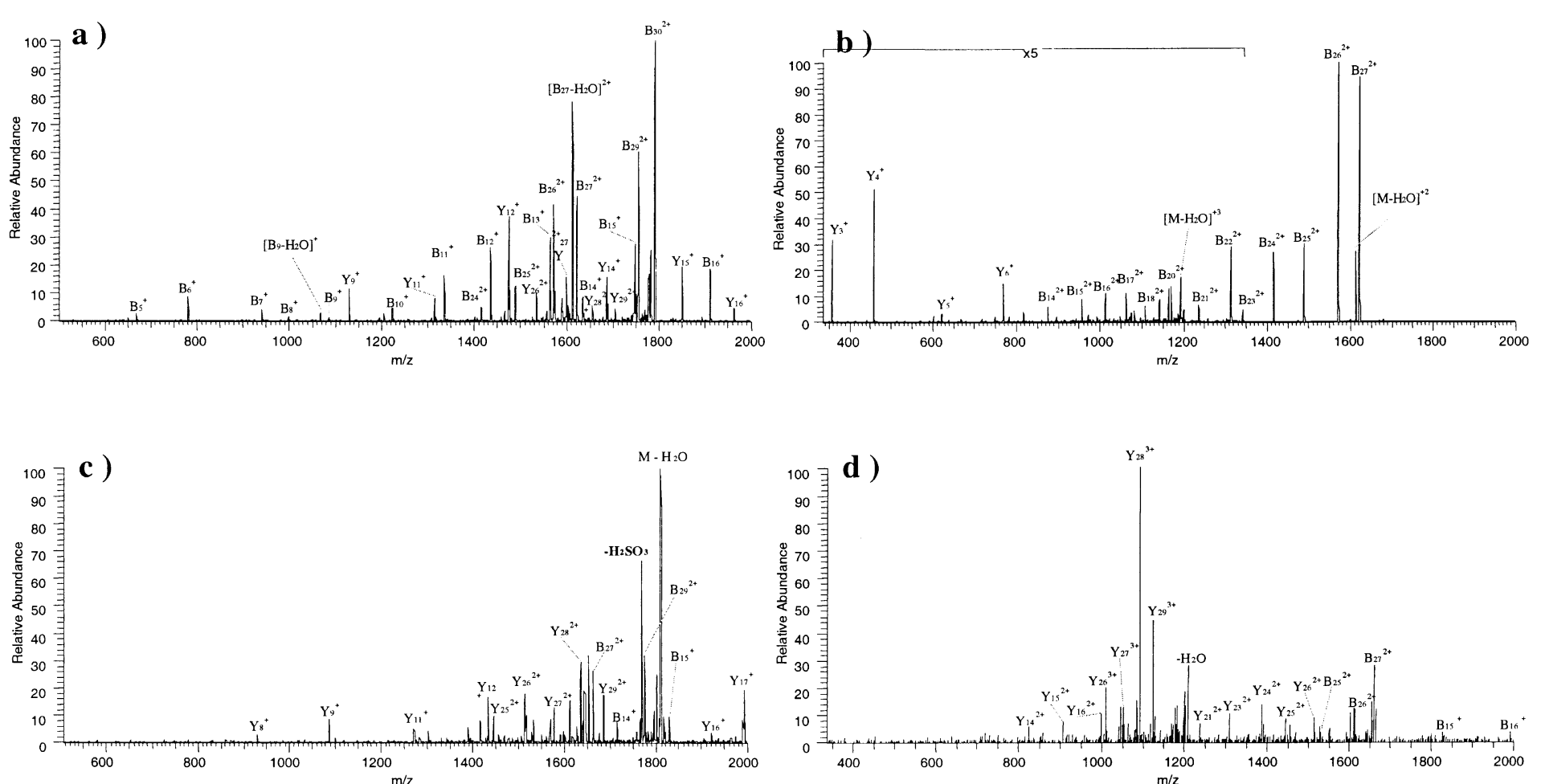

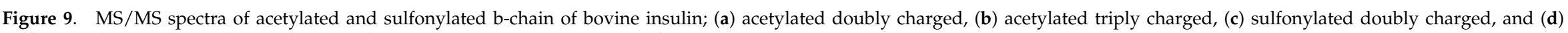
sulfonylated triply charged. Acetylation is done with $\mathrm{N}$-terminus and Lys, sulfonylation only at the $\mathrm{N}$-terminus. 
partial loss of the reagent helps to identify unambiguously the N-terminal amino acids.

\section{Conclusions}

The fragmentation of glucagon and alkylated b-chain of bovine insulin has been investigated. Charge state and derivatization have been found to have a strong influence on the dissociation behavior. The preformed charge of the derivative in particular plays an important role in the fragmentation process of the peptide. Moreover, it was possible to shift the region of fragmentation on the b-chain of bovine insulin by the choice of the derivatizing reagent. By introducing a positive charge, the focus of fragmentation can be directed to the C-terminus while a negative charge shifts the fragmentation to the N-terminus. The specificity of the derivatization reaction is a crucial step. Acetylation of the $\mathrm{b}$-chain has led to a complete suppression of $y$-fragment ions, which facilitates the interpretation of the spectrum. It has been proven that the derivatization reactions are also able to improve the information content of the spectra obtained from multiply charged precursor ions.

The instability of chloro-sulfonylacetyl-chloride derivatization is useful to identify the $y$-fragment ion series, whereas the instability of tri-phenyl-phosphine leads to additional fragment ions. An instability of the acetylated peptides was not observed.

From these investigations we conclude that the described derivatizations are useful to get sequence information on specified areas of the peptide. Following Keough et al. [35], the derivatization with chloro-sulfonylacetyl-chloride is applicable on tryptic in-gel digestions with a total amount of $300 \mathrm{fmol}$ of protein. Basic residues and specific amino acids (Asp, Pro) have a significant influence on the dissociation behavior. Therefore further investigations are necessary to generalize the practicability of the derivatization reactions for de novo sequencing of larger multiply charged peptides. Specifically, the general ability to control fragmentation on multiply charged peptides has to be proven by further investigations.

\section{References}

1. Henzel, W. J.; Billeci, T. M.; Stults, J. S.; Wong, S.C.; Grimley, C.; Watanabe, C. Identifying Proteins from 2-Dimensional Gels by Molecular Mass Searching of Peptide Fragments in Protein Sequence Databases. Proc. Natl. Acad. Sci. U.S.A. 1993, 90, 5011-5015.

2. Billeci, T. M.; Stults, J. S. Tryptic Mapping of Recombinant Proteins by Matrix-Assisted Laser Desorption/Ionization Mass Spectrometry. Anal. Chem. 1993, 65, 1709-1716.

3. Whittal, R. M.; Keller, B. O.; Li, L. Nanoliter Chemistry Combined with Mass Spectrometry for Peptide Mapping of Proteins from Single Mammalian Cell Lysates. Anal. Chem. 1998, 70(24), 5344-5347.

4. Pandey, A.; Mann, M. Proteomics to Study Genes and Genomes. Nature 2000, 405, 837-846.

5. Pitt, A. R. Application of Electrospray Mass Spectroemetry in
Biology. Nat. Prod. Reports 1998, 59-72.

6. Marie, G.; Serani, L.; Laprévote, O. An On-Line Protein Digestion Device for Rapid Peptide Mapping by Electrospray Mass Spectrometry. Anal. Chem. 2000, 72(21), 5423-5430.

7. Roepstorff, P.; Fohlman, J. Proposal for a Common Nomenclature for Sequence Ions in Mass Spectrometry. J. Biomed. Mass Spectrom. 1984, 11, 601.

8. Smith, R. D.; Loo, J. A.; Edmonds, C. G.; Barinaga, C. J.; Udseth, H. R. Perspective: Analytical Biotechnology, New Developments in Biochemical Mass Spectrometry: Electrospray Ionization. Anal. Chem. 1990, 62, 882-899.

9. Knapp, D. R. Chemical Derivatization for Mass Spectrometry. Methods Enzymol. 1990, 193, 314-348.

10. Roth, K. D. W.; Huang, Z.-H.; Sadagopan, N.; Watson, J. T. Charge Derivatization of Peptides for Analysis by Mass Spectrometry. Mass Spectrom. Rev. 1998, 17, 255-274.

11. Huang, Z.-H.; Shen, T.; Wu, J.; Gage, D. A.; Watson, J. T. Protein Sequencing by Matrix-Assisted Laser Desorption Ionization-Postsource Decay-Mass Spectrometry Analysis of the N-Tris(2,4,6-trimethoxyphenyl) Phosphine-Acetylated Tryptic Digests. Anal. Biochem. 1999, 268, 305-317.

12. Liao, P.-C.; Huang, Z.-H.; Allison, J. Charge-Remote Fragmentation of Peptides Following Attachment of a Fixed Positive Charge: A Matrix-Assisted Laser Desorption/Ionization Postsource Decay Study. J. Am. Soc. Mass Spectrom. 1997, 8, 501-509.

13. Sadagopan, N.; Watson, J. Investigation of the Tris(trimethoxyphenyl) Phosphonium Acetyl Charged Derivatives of Peptides by Electrospray Ionization Mass Spectrometry and Tandem Mass Spectrometry. J. Am. Soc. Mass Spectrom. 2000, $11,107-119$.

14. Tang, X.-J.; Thibault, P.; Boyd, R. K. Fragmentation Reactions of Multiply Protonated Peptides and Implications for Sequencing by Tandem Mass Spectrometry with Low-Energy Collision-Induced Dissociation. Anal. Chem. 1993, 65, 28242834.

15. Jones, J. L.; Dongré, A. R.; Somogyi, Á.; Wysocki, V. H. Sequence Dependence of Peptide Fragmentation Efficiency Determined by Electrospray Ionization/Surface/Induced Dissociation Mass Spectrometry. J. Am. Chem. Soc. 1994, 116, 8368-8369.

16. Dongré, A. R.; Jones, J. L.; Somogyi, A.; Wysocki, V. H. Influence of Peptide Composition, Gas-Phase Basicity, and Chemical Modification on Fragmentation Efficiency: Evidence for the Mobile Proton Model. J. Am. Chem. Soc. 1996, 118, 8365-8374.

17. Gu, C; Somogyi, A; Wysocki, V. H.; Medzihradshky, K. F. Fragmentation of Protonated Oligopeptides XLDVLQ (X $=\mathrm{L}$, H, K, or R) by Surface-Induced Dissociation: Additional Evidence for the Mobile Proton Model. Anal. Chim. Acta. 1999, 397, 247-256.

18. Downard, K. M.; Biemann, K. The Effect of Charge State and the Localization of Charge on the Collision-Induced Dissociation of Peptide Ions. J. Am. Soc. Mass Spectrom. 1994, 5, 966-975.

19. Downard, K. M.; Biemann, K. Charging Behavior of HighlyBasic Peptides During Electrospray Ionization. A Prediction for Protons. Int. J. Mass Spectrom. Ion Processes 1995, 148, 191-202.

20. Burlet, O.; Yang, C.-Y.; Gaskell, S. J. Influence of Cysteine to Cysteic Acid Oxidation on the Collision-Activated Decomposition of Protonated Peptides: Evidence for Intraionic Interactions. J. Am. Soc. Mass Spectrom. 1992, 3, 337-344.

21. Cox, K. A.; Gaskell, S. J.; Morris, M.; Whiting, A. Role of the Site of Protonation in the Low-Energy Decompositions of Gas-Phase Peptide Ions. J. Am. Soc. Mass Spectrom. 1996, 7, 522-531. 
22. Keough, T.; Youngquist, R. S.; Lacey, M. P. A Method for High-Sensitivity Peptide Sequencing Using Postsource Decay Matrix-Assisted Laser Desorption Ionization Mass Spectrometry. Proc. Natl. Acad. Sci. U.S.A. 1999, 96, 7131-7136.

23. Bauer, M. D. Y.; Sun, Y.; Keough, T.; Lacey, M. P. Sequencing of Sulfonic Acid Derivatized Peptides by Electrospray Mass Spectrometry. Rapid Commun. Mass Spectrom. 2000, 14, 924929.

24. Glocker, M. O.; Borchers, C.; Fiedler, W.; Suckau, D.; Przybylski, M. Molecular Characterization of Surface Topology in Protein Tertiary Structures by Amino-Acylation and Mass Spectrometric Peptide Mapping. Bioconj. Chem. 1994, 5, 583590.

25. Keough, T.; Youngquist, R. S.; Lacey, M. P. A method for High-Sensitivity Peptide Sequencing Using Postsource Decay Matrix-Assisted Laser Desorption Ionization Mass Spectrometry. Proc. Natl. Acad. Sci. U.S.A. 1999, 96, 7131-7136.

26. Keough, T.; Lacey, M. P.; Fieno, M.; Grant, R. A.; Sun, Y.; Bauer, M. D.; Begley, K. B. Tandem Mass Spectrometry Methods for Definitive Protein Identification in Proteomics Research. Electrophoresis 2000, 21, 2252-2265.

27. Wagner, D. S.; Salari, A.; Gage, D. A.; Leykam, J.; Fetter, J.; Hollingsworth, R.; Watson, J. T. Derivatization of Peptides to Enhance Ionization Efficiency and Control Fragmentation During Analysis by FAB-MS. Biol. Mass Spectrom. 1991, 20, 419-425.

28. Yu, W.; Vath, J. E.; Huberty, M. C.; Martin, S. A. Identification of the Facile Gas-Phase Cleavage of the Asp-Pro and Asp-Xxx Peptide Bonds in Matrix-Assisted Laser Desorption Time-of-
Flight Mass Spectrometry. Anal. Chem. 1993, 65, 3015-3023.

29. Gu, C.; Tsaprailis, G.; Breci, L.; Wysocki, V. H. Selective Gap-Phase Cleavage at the Peptide Bond Terminal to Aspartic Acid in Fixed-Charge Derivatives of Asp-Containing Peptides. Anal. Chem. 2000, 72, 5804-5813.

30. Schwartz, B. L.; Bursey, M. M. Some Proline Substituent Effects in the Tandem Mass Spectrum of Protonated Pentaalanine. Biol. Mass Spectrom. 1992, 21, 92-96.

31. Willard, B. B., Kinter, M. Factors Affecting Amino Acid Sequence Information in CID-Spectra of Triply Charged Tryptic Peptides with an Internal Histidine. Proceedings of the ASMS Conference. June 2000, Long Beach, CA.

32. Bunk, D. M.; Macfarlane, R. D. Derivatization to Enhance Sequence-Specific Fragmentation of Peptides and Proteins. Int. J. Mass Spectrom. Ion Processes 1993, 126, 123-126.

33. Wagner, D. S.; Salari, A.; Gage, D. A.; Leykam, J.; Fetter, J.; Hollingsworth, R.; Watson, J. T. Derivatization of Peptides to Enhance Ionization Efficiency and Control Fragmentation During Analysis by FAB-MS. Biol. Mass Spectrom. 1991, 20, 419-425.

34. Miyagi, M.; Nakao, M.; Nakazawa, T.; Kato, I.; Tsunasawa, S. A Novel Derivatization Method with 5-Bromo-Nicotinic Acid N-Hydroxysuccinimide for Determination of the Amino Acid Sequences of Peptides. Rapid Commun. Mass Spectrom. 1998, 12, 603-608.

35. Keough, T.; Lacey, M. P.; Fieno, M.; Grant, R. A.; Sun, Y.; Bauer, M. D.; Begley, K. B. Tandem Mass Spectrometry Methods for Definitive Protein Identification in Proteomics Research. Electrophoresis 2000, 21, 2252-2265. 